Journal of Engineering and Applied Sciences 14 (3): 945-950, 2019

ISSN: 1816-949X

(C) Medwell Journals, 2019

\title{
A Study on the Prevention of Smombie's Accidents by Satellite Information
}

\author{
Ik-Soo Ahn and Myung-Jin Bae \\ Department of Information and Telecommunication, Soongsil University, 369 Sangdo-ro, \\ Dongjak-gu, Seoul, Korea
}

\begin{abstract}
Smombie (Smartphone+Zombie) is a new word meaning smartphone addict. It is named because it is like a Zombie when walking around while watching a smartphone. The Smombies are increasing in proportion to the spread of smart phones and the development of application functions of smart phones and also accidents are increasing which is becoming a serious social problem. In this study, we propose to add a system that generates a warning sound in the smartphone itself to prevent accidents caused by Smombies. A study on the prevention of accidents caused by Smombies occurred in warning sounds when start walking while watching a smartphone but it is not used well because of the ineffective beep in too wide a situation. In order to compensate for such shortcomings, this study is a study on aggressive prevention system that can prevent danger by ringing a warning sound by checking the distance, access speed and scale between the smartphone and the dangerous places and objects. The Smombie accident prevention system uses a function of sharing a Wireless Sensor Network (WSN), a Global Position System (GPS) and a Geographical Information System (GIS) using a satellite.
\end{abstract}

Key words: Smartphone, Zombie, accident prevention, warning sound, satellite, system

\section{INTRODUCTION}

The new word 'Smombie', a combination of a smartphone and a Zombie, It is a term used to refer to a person who is addicted to a smartphone and who walks while walking on the street without a soul. The function of the smartphone fascinates humans and falls enough to become addictive, so, it gets immersed when walking, so, it can be seen as if there is no soul. This phenomenon has caused various accidents and has become a social problem in many countries of the world. In this age, smart phones are a useful device for everyone to own as a necessity. Besides the other side of the earth as well as those in outer space, you can do video calls as well, you can quietly send and receive letters with SNS (Social Net-work Service), also search various information Then, using various applications, games can also be enjoyed. In addition, the functions of the smartphone are combined with the functions of $\mathrm{AI}$ (Artificial Intelligence) and IoT (Internet of Technology) and are entering a new age far beyond the ubiquitous environment. In particular, gradually turning into a family's era in nuclear families and challenging marriage and childbirth, recently he has also played the role of a personal secretary and healed loneliness. However, the more features of smartphones are the more people are seen being addicted to poisoning phenomena which is a problem of a new modern society.
The poisoning phenomenon is a big problem in immersing in smart phones while walking on the street (Hyung-Jin et al., 2007; Sang-Hyuk and Chang-Dong, 2011; Dong, 2013; Kyu-Young and Yoon-hee, 2014; Jang et al., 2013; Seok-Yong etal., 2012; Bum etal., 2012).

\section{MATERIALS AND METHODS}

Addiction status of smartphone: Smartphones are able to socialize with others through information sharing and interactive communication and Social Network Service (SNS) and can lead a wider life through information retrieval, various applications, games and music appreciation. However, excessively immersed in smartphones, they can't concentrate on other things and malfunctioning problems that can not escape from smartphone as soon have occurred. In particular, the younger the age, people fall into the charm easily in the smartphone's environment because self-deterrence is poor. unconsciously seeing the smartphone, the behavior became a habit and changed into poisoning. Smartphone addiction makes it impossible for you to stay away from smartphones for a moment and even when you have a smartphone, you are constantly looking into it and feel nervous about doing something. These smartphone poisoning phenomena finally, got to the custom which I can not keep my eyes on smartphones while walking the

Corresponding Author: Myung-Jin Bae, Department of Information and Telecommunication, Soongsil University, 369 Sangdo-ro, Dongjak-gu, Seoul, Korea 
Table 1: Addiction status of smartphone

\begin{tabular}{|c|c|c|c|c|c|c|c|}
\hline \multirow[b]{2}{*}{ Division } & \multirow[b]{2}{*}{ When not using smartphone } & \multicolumn{5}{|c|}{ When using smartphone } & \multirow[b]{2}{*}{ Sum } \\
\hline & & Phone & Music & Text & Music+Text & Sub total & \\
\hline \multirow[t]{2}{*}{ General } & 650 & 68 & 54 & 191 & 245 & 313 & 963 \\
\hline & $67.5 \%$ & $7.1 \%$ & $5.6 \%$ & $19.8 \%$ & $25.4 \%$ & $32.5 \%$ & $100.0 \%$ \\
\hline Cross & 1.032 & 34 & 138 & 192 & 330 & 364 & 1,396 \\
\hline walks & $73.9 \%$ & $2.4 \%$ & $9.9 \%$ & $13.8 \%$ & $23.6 \%$ & $26.1 \%$ & $100.0 \%$ \\
\hline
\end{tabular}

National Security Agency Press Release

road. Table 1 shows the actual usage of smartphone during walking on both general and crosswalks (Hyung-Jin et al., 2007; Sang-Hyuk and Chang-Dong, 2011; Hoon and Myung, 2007; Bum et al., 2012; Moon and Dae, 2015; Kyoung and Jin, 2015; Sang-Hwi et al., 2017).

As of 2015 , the use of smartphones during walking was most often transmitted while listening to music, followed by letter transfer, music and voice calls in that order. In addition, information retrieval, application use, games, etc. are mainly used and many people till watching TV and movies. Smombies that walk around the smartphone have a narrow field of view and dispersed concentration which greatly increases the risk of accidents. Even, those who still have little Smombie symptoms can be seen as having a potential accident risk attributable to whom the Smombie phenomenon is attributable to the reality that more than $90 \%$ of the people currently using smartphones are using smartphones (Sang-Hyuk and Chang-Dong, 2011; Dong, 2013; Eugene, 2018; Bae et al., 2013; Bae and Kim, 2013; Bae and Bae, 2017; Cho and Kim, 2014; Hong and Bae, 2007; Jung and Bae, 2007).

\section{RESULTS AND DISCUSSION}

Risk of accidents due to Smombies: When people walk around, the viewing angle can be from $120-150^{\circ}$, so, you can walk around with a clear view. But when people using a smartphone, the viewing angle is reduced from $10-20^{\circ}$ when you walk. Reduced viewing angle means that it is difficult to recognize the danger and it is difficult to deal with the dangerous situation immediately. Recently, in New York in the United States as accidents caused by Smombies increase rapidly, controversies are taking place with a penalty plan for those who make smartphone messages while walking along the road. The accident caused by Smombies is a problem in the whole world as well as in the United States such as crashing into a pole or falling on a wall, falling into a open the road hole, suddenly walking on the road and getting a traffic accident (Fig. 1).

About $95.7 \%$ of smartphone users have experienced using walking smartphones, $25 \%$ said they had experienced an accident at a crosswalk. Distinguishing
Table 2: Distance awareness of smartphone users while walking by ages

\begin{tabular}{lllll}
\hline Smombie status/Ages & 20 's & 30 's & 40 's & 50 's \\
\hline Smombie & 15 & 15 & 15 & 12.5 \\
No Smombie & 10 & 8.8 & 7.5 & 2.5 \\
\hline
\end{tabular}

Joongang Daily May 11, 2016

distance recognition ability during walking by age into smartphone usage (Smombie) and non-use (non-Smombie), the smartphone user walking as the age increases, the phenomenon that distance recognition ability decreases markedly. It is very dangerous as it will show (Table 2).

In case of our country: Korea is an IT powerhouse that has the highest penetration rate of the internet and smartphones. It has more than one smartphone per citizen, not only Kindergarten students, elementary school students but also elderly people over 80 years old. Also, the function of the smartphone is getting more and more. and it is called as a computer on the palm as clearly having the same sound quality and picture quality that it talks with the person on the other side of the earth from voice call to video call. Based on such functions, the application was installed and it became the era where various information such as game, map retrieval, route order function etc can be utilized. Such an exciting and enjoyable smartphone falls into a smartphone moving on public transportation even if he/she fixes his/her eyes and meet his friends. In the end, the problem is serious because there are people who are looked in smartphones while driving and large accidents occur. Among them, Smombie who uses a smartphone while walking, leans his head in a bent posture with his/her earphones, bumps into his/her head and does not change the signal of the pedestrian crossing. According to traffic safety corporation's 'study on correlation between usage of smartphone and walking accident' in 2013, pedestrians walking on a smartphone showed a $76 \%$ increase in risk of accidents. The use of smartphones reduces visibility, auditory attention and cognitive ability and coping with the risk of accidents is slowed, leading to major accidents. According to the survey of traffic accidents due to the Smombies by Hyundai Marine and Navy in Fig. 2 from 2009-2015, the number of accidents from 437 cases in 2009 rapidly increased to 1.360 cases in 2015 , about 3.1 times. 
(a)

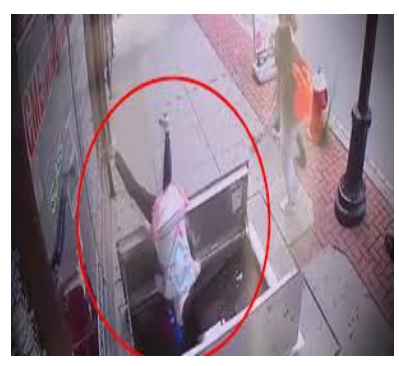

(b)

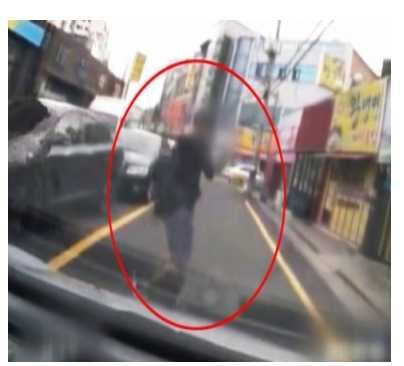

(c)

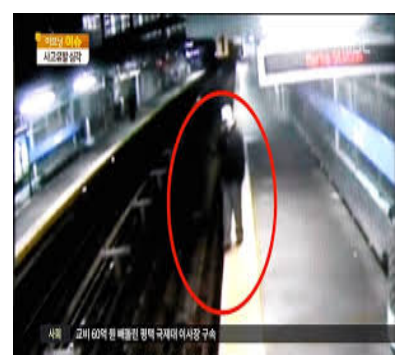

Fig. 1: Walking accident by Smombies: a) Sidewalk accident; b) Crosswalk accident and c) Train platform accident (MBC News Desk May 18, 2016, Yonhap News June 10, 2017)

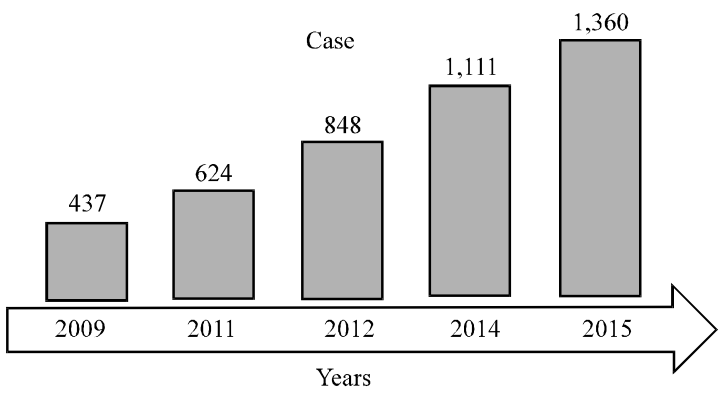

Fig. 2: Increase in traffic accidents by Smombie (2015 Hyundai Marine and Fire)

As, we investigated the tendency for accidents caused by Smombies to increase more and more the problem of Korea's Smombies are also a serious situation.

Prevention measures of Smombies accident in many countries around the world: In many parts of the world, accidents caused by Smombies are a serious social problem. When using a smartphone while walking, the angle of view becomes significantly narrower and the recognition rate of accidents decreases accordingly. In Korea, $95.5 \%$ of the respondents who answered the questionnaire survey answered that they use smartphone during walking. The use of smartphones during such walking causes serious accidents such as road accidents and crashes as well as traffic accidents. As a result, in order to prevent the Smombie accidents in the United States, New York City, Honolulu, Hawaii, Shanghai, China, imposed fines to restrict the use of smartphones while on the move. In addition, many countries in the world including Korea are attempting various measures such as making a special road for the safety of the Smombies on the screen of the smartphone, installing a warning sign, a sticker and a floor signal.

Special walkway for Smombie accident prevention: It is a pedestrian walkway that sets the direction of walking to the left and the right by cutting the line separately from the place where the general people walk on one side of side walk in order to prevent accidents by the Smombies. After making the Smombies only walkway, people who use their smartphone walk away from the other side of the road is no worries. Currently, there is a pedestrian walkway dedicated to Smombies such as Antwerp Street in Belgium, Chongqing Street in China and Bangkok in Thailand (Fig. 3).

Caution signs for Smombie accident prevention: The Smombie accident sign is a sign that tells the public and Smombies to watch out for frequent accidents such as crashes or unauthorized crossing. In Sweden and New York, we installed a sign such as "smartphone attention while walking" and it has spread to various countries and its name has been variously called.

In Sweden, the sign of the Smombie accident was called "look up, people" and the sign shows two people walking down the street with their smartphone screen. In Korea, the sign of the Smombie accident in the intersection, near the pedestrian crossing, the back road, etc., is put in the phrase "smartphone caution while walking" (Fig. 4).

Floor LED traffic lights for Smombie accident prevention: The floor LED traffic light is a traffic light that draws a line with an LED signal light on the floor or a square area to prevent accidents from occurring in the vicinity of a road from a pedestrian crossing or a pedestrian road to prevent accidents caused by Smombies. Smombies are walking on their smartphones, so, they have their heads folded, so, they have focused their attention on the floor and made LED lights on the floor. The name of the LED traffic light installed on the roads in Augsburg, Germany is called Bompeln which is a combination of two words, Boden and Ampeln. Currently, not only in Germany but also in Singapore, the 
(a)

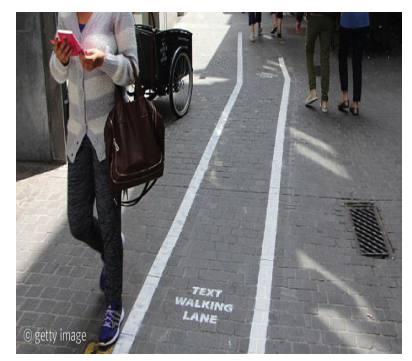

(b)

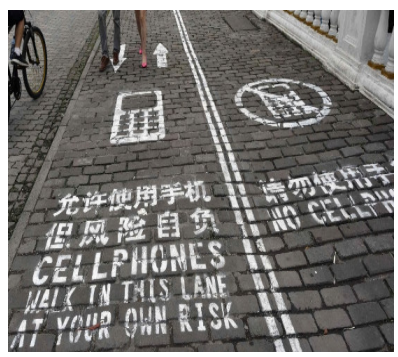

(c)

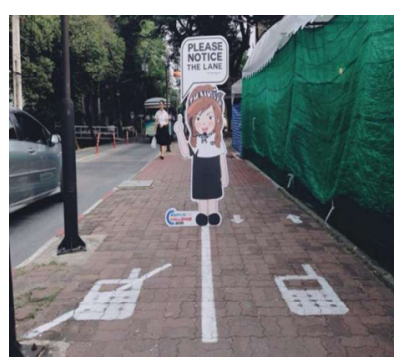

Fig. 3: Special walkway for Smombie accident prevention: a) In Belgium; b) In China and c) In Thailand (SBS Articles December 7, 2016)

(a)

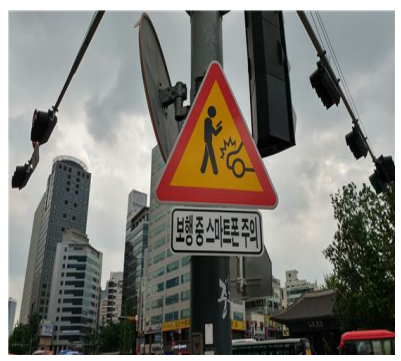

(b)

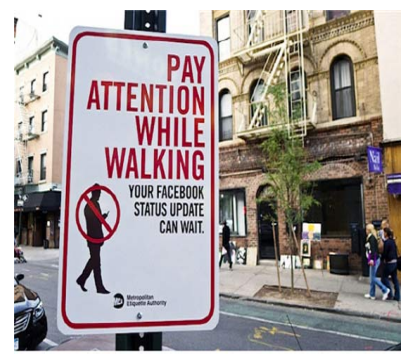

(c)

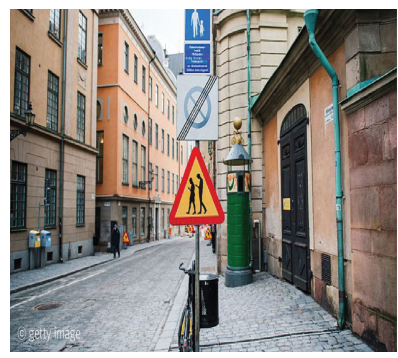

Fig. 4: Caution signs for Smombie accident prevention: a) In Korea; b) In America and c) In Sweden (SBS 8 City News December 7, 2016)

(a)

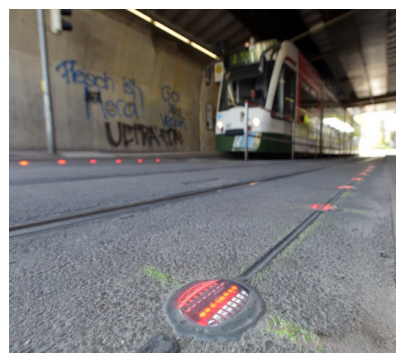

(b)

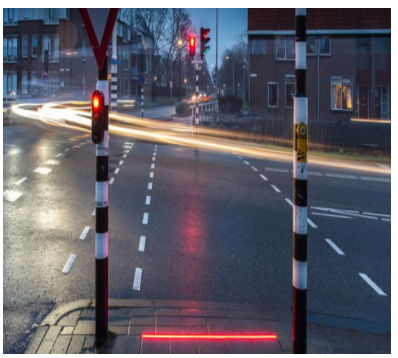

(c)

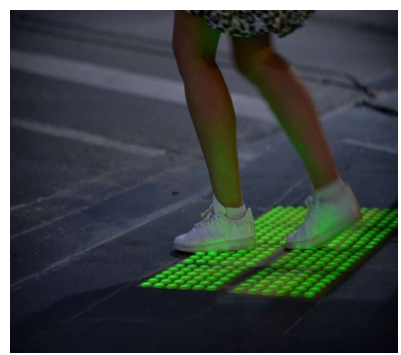

Fig. 5: Floor LED traffic lights for Smombie accident prevention: a) In Germany; b) In Netherlands and c) In Canada (Joongang Daily May 10, 2017)

Netherlands and Canada, there is a floor traffic light to prevent Smombie accidents in India which is crossing the pedestrian crossings (Fig. 5).

Sticker for Smombie accident prevention: In Korea, stickers are made for more aggressive Smombie accident prevention systems and are attached to the bottom of India or to the snowy area near the crosswalk. Yet, the dedicated walkway or floor LED traffic light is not active but it uses caution signs and stickers to prevent Smombie accidents. The Seoul metropolitan government set up a prototype of 250 smartphone warning signs and 50 cover signs near 5 crosswalks including Seoul City Hall which has a large population in June. The government plans to expand the system nationwide by designating it as a regular traffic safety facility when the effectiveness of such facilities is proved (Fig. 6).

\section{Warning sound system for Smombie accident prevention:} In Korea, various methods are being tried to prevent Smombie accidents. In the 21 st century, Information and Communication Technologies (ICT) based on the digital environment of contemporary society has been developed in the internet environment (IoT: Internet of Technology) and artificial intelligence (AI: Artificial Intelligence) technology and the future new growth power, the 4th 
(a)

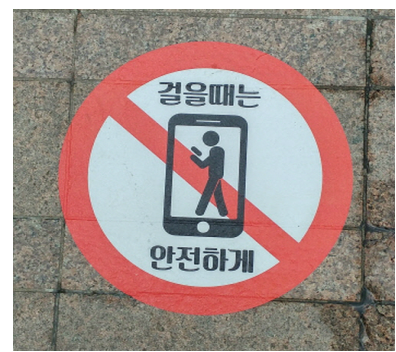

(b)

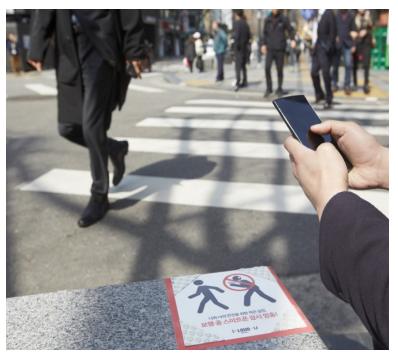

(c)

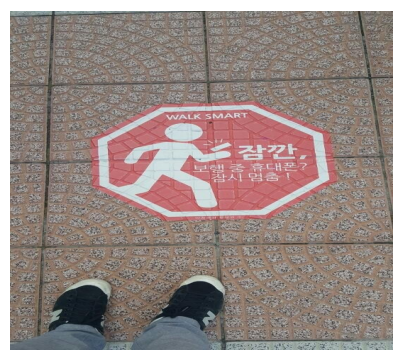

Fig. 6a-c: Sticker for Smombie accident prevention (Good, AsiaNews, jacob and emil, loud project, financial news September 11, 2016)

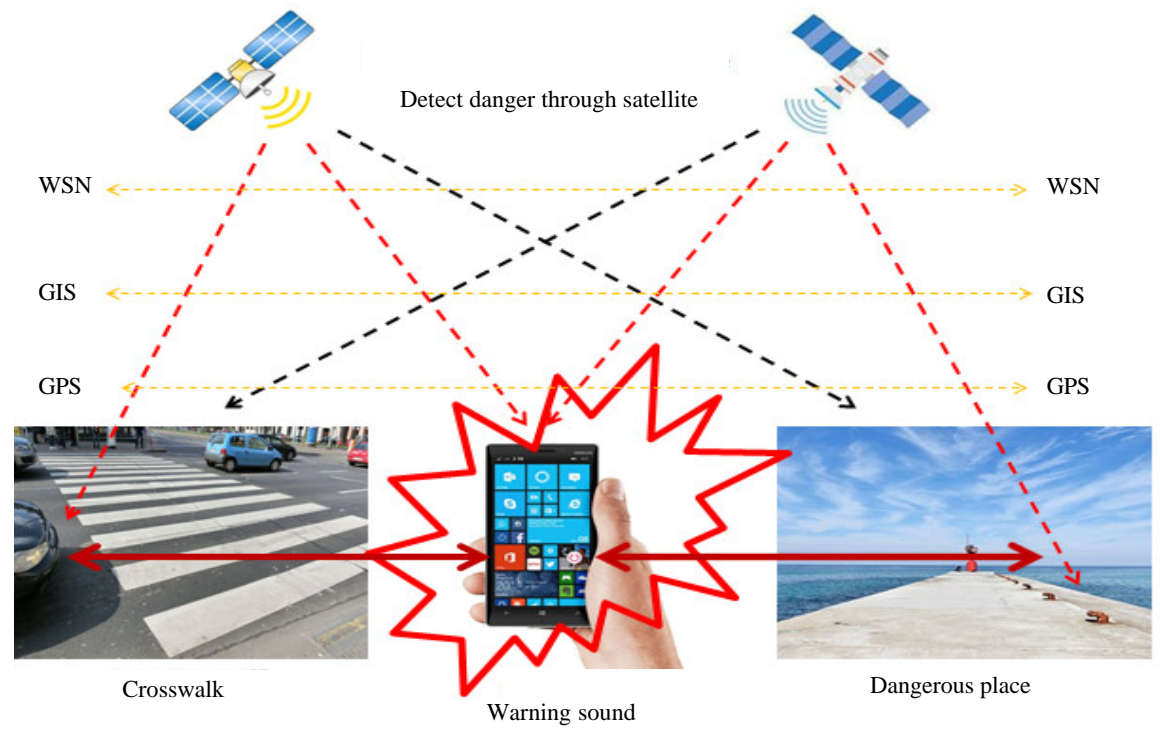

Fig. 7: Warning sound system for Smombie accident prevention

industrial revolution. The system for accident prevention is based on IOT and AI based on information and communication technology. It is based on a Wireless Sensor Network (WSN), a Global Positioning System (GPS) and a Geographic Information System (GIS) system) is used to share the navigation function. Kyu-Young and Yoon-hee (2014) satellites transmit GPS and map Information System (GIS) which enable location tracking of smart phones under the Wireless Sensor Network (WSN) environment, to the smartphone of Smombies. The transmitted location information and the map information confirm the exact distance and time from the surrounding dangerous environment while the Smombie is walking and allow the smartphone to recognize an unknown object or dangerous place approaching the Smombie. The Smombie warning sound system is a system that prevents the accident from occurring by generating a beep when the various information is input and analyzed in real time on the mobile and the danger is detected. The warning sound system for the prevention of Smombie accidents should be mandatory when the smartphone is released and existing smartphones should be added to the navigation function or developed as new applications for free use (Soon-Hee, 2015; Cho and Kim 2014) (Fig. 7).

\section{CONCLUSION}

A smartphone that has become a necessity for modern people is not the right device if it poisoned people and made them foolish and cause various accidents. As the science and technology develops, the result should be convenient, beneficial and safe, so that, it is close to perfection for people. Smartphones are constantly evolving with communication, information, entertainment and safety in mind but safety accidents caused by smartphone addiction are not diminishing. In this study, we focused on the fact that various accidents caused by so-called Smombies using smartphone while 
walking are occurring as much as incidents that occur using smartphone while walking. During the walk, the smartphone accident uses the GPS and the map Information System (GIS) to enable the location tracking of the smartphone under the Wireless Sensor Network (WSN) environment. The system that generates a warning sound is studied. This system must be installed in hardware or software as an essential part of the smartphone production stage and should be installed as an application in the already released smartphone. The accidents caused by the Smombie phenomenon should not be confined to personal problems but should be urgently set up in various social and national aspects with various preventive measures (Eugene, 2018).

\section{REFERENCES}

Bae, M. and M. Kim, 2013. Professor Bae's Sound Story. Gimm-Young Publishers, Seoul, South Korean,

Bae, S., M. Kim and M. Bae, 2013. On enhancement signal using non-uniform sampling in clipped signals for LTE smart phones. Proceedings of the ICCE Berlin 2013 IEEE 3rd International Conference on Consumer Electronics Berlin (ICCE-Berlin'13), September 9-11, 2013,IEEE, Berlin, Germany, ISBN:978-1-4799-1412-8, pp: $129-130$.

Bae, S.G. and M.J. Bae, 2017. A study on recovery in voice analysis through vocal changes before and after specch using speech signal processing. Intl. J. Appl. Eng. Res., 12: 5299-5303.

Bum, P., L. Min-Seop and P. Joonhong, 2012. Comparison of sound emission characteristics of diesel engine and gasoline engine sound and artificial engine sound synthesis for sound quality evaluation. Korean Soc. Mech. Eng., 1: 1590-1591.

Cho, G.Y. and Y.H. Kim, 2014. Influencing factors of college student smartphone addiction. J. Korean Acad. Soc. Ind. Sci., 15: 1632-1640.

Dong, I.L., 2013. Traffic safety accident prevention smart safety operation system. Small and Medium Business Administration, South Korea.

Eugene, L., 2018. A user-experience study on accident prevention service for pedestrians using smartphones while walking. Master Thesis, Ewha Womans University, Seoul, South Korea.
Hong, S.H. and M.J. Bae, 2007. A study on the sound that raises the concentration. IEICE. Conf. Comput. Commun., 30: 671-672.

Hoon, H.S. and J.B. Myung, 2007. A study on the sound enhancement of concentration. IEICE., 30: 671-672.

Hyung-Jin, P., H. Hyeong-Joo and S. Hyun-Joo, 2007. A study on driver characteristics in a long tunnel using simulator. J. Ergon. Soc. Korea, 26: 89-102.

Jang, S.Y., S.J. Kim and S.S. Goh, 2013. A study on the reduction of traffic accidents by analyzing characteristics of smartphone usage during driving: Applying Ajzen's theory of planned behavior. Kerala State Road Transport Corporation, Thiruvananthapuram, India.

Jung, C.J. and M.J. Bae, 2007. A study on the classification of surprising sounds. Acoust. Soc. Korea, 26: 57-58.

Kyoung, S.Y. and B.M. Jin, 2015. Psychoacoustic study of automobile engine sound. Acoust. Soc. Korea, 34: 180-180.

Kyu-Young, C. and K. Yoon-hee, 2014. Influencing factors of smartphone addiction in college students. J. Korean Acad. Soc. Ind. Sci., 15: 1632-1640.

Moon, K.B. and Y.Y. Dae, 2015. Design of a green car virtual engine sound generator. Korean Inst. Electr. Eng., 1: 93-94.

Sang-Hwi, J., K. Myung-Sook and B. Myung-Jin, 2017. On designing a new sound of the car-horn. J. Acoust. Soc. Am., 141: 3494-3494.

Sang-Hyuk, P. and Y. Chang-Dong, 2011. Efficient real-time drowsy detection algorithm for safe operation. Conf. Electron. Eng. Soc. Korea, 6: 947-950.

Seok-Yong, J., H.Y. Jung, D.S. Park and S.S. Ko, 2012. A study on the effects smartphones have on safety when used while driving. Traffic Res., 19: 75-91.

Soon-Hee, J., 2015. A study on the relationship between social development and ego resilience of middle school students and smartphone addiction. Master Thesis, Woosuk University, Wanju County, South Korea. 